\title{
Médecine des peluches
}

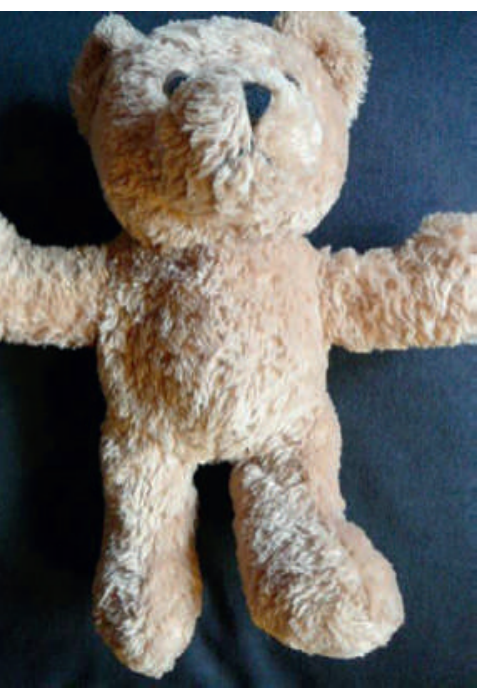

Pour la plupart des gens, les peluches représentent les fidèles amies du jeune âge, bien plus que des jouets d'enfants. Elles sont aides au développement, intermédiaires dans le dialogue avec soi et les autres, interlocutrices et compagnes de jeu. Elles consolent et protègent. Le bouton dans l'oreille de Steiff symbolise une éclatante réussite, à laquelle le président américain Theodore Roosevelt et son surnom «Teddy» ont nettement contribué. La psychiatrie les considère comme des objets de transition qui nous aident à surmonter l'angoisse des séparations, les pertes et les chagrins réels. Linus et sa couverture doudou de la BD de Charles M. Schulz ou Calvin et son tigre en peluche Hobbes, imaginés par Bill Watterson, ont popularisé la notion scientifique dans le monde entier. Les douces chuchoteuses et leurs collègues les poupées ont le vent en poupe. Les pédagogues, les historiens, les dessins animés et, depuis plusieurs années, les hôpitaux, leur consacrent leur attention. De la naissance à la maison de retraite, nos amis à fourrure semblent jouer un rôle décisif sur les plans sociaux, de communication, socio-émotionnels, préventifs, spécifiques au genre et interculturels.

Autrefois jetés aux ordures une fois abîmés, donc évincés de nos biographies, ils sont en passe de devenir des objets cultes et choyés. La première clinique pour nounours a vu le jour en Suède. Depuis, presque toutes les facultés de médecine ont la leur. Le Stadtspital Waid à Zurich ne fait pas exception. Sur tous ces sites, les étudiants en médecine et médecins se rendent dans les jardins d'enfants et aux événements de quartier ou proposent certains jours des consultations, avec pose de plâtres, radios, drainages lymphatiques et interventions mini-invasives, comme l'ablation d'un œuf de Pâques. D'autres cliniques pour nounours proposent des offres de spa, de Total Face Care et de manucure. Des patients enroués y retrouvent leur grosse voix grâce à des Vocal Coaches, d'autres, souffrant de burn-out, se font rembourrer la panse ou recoudre leurs yeux de verre. Les actions de chouchoutage font partie de la stratégie de RP de nombreux hôpitaux car cette mignonne promotion de l'image de marque vise, sous couvert de pédagogie, à conquérir de nouveaux clients. Une opération séduction qui semble porter ses fruits, puisque d'autres branches suivent. Des agences pour peluches organisent des vacances détente ou aventure. Les doudous, représentants à part entière de leurs propriétaires, envoient des cartes postales des villes visitées aux amis restés à la maison. Ce que les yeux de Lapinou ont découvert est remis en vidéo à son maître. Ce service est utilisé par des personnes malades, handicapées, désargentées, à court de temps ou trop âgées pour voyager. Les célibataires qui ne veulent pas manger seuls au restaurant ont droit à une poupée comme compagne de table. Si elle avait une voix, comme le système d'exploitation dans la comédie de science-fiction romantique «Her» (2013), elle pourrait devenir notre objet préféré. Mais la technologie n'est pas indispensable, comme le montre Tom Hanks dans le film «Seul au monde» (2000). Echoué sur une île, un ballon de volley peint l'aide à traverser l'enfer de la solitude sans sombrer dans la folie. L'affection des Japonais pour les robots a aussi des origines culturelles. Le shintoïsme intègre de nombreux rituels pour les objets personnels comme les membres à poils synthétiques de la famille. Chaque année, il est possible de faire ses adieux à ses compagnons usagés lors d'enterrements de poupées dirigés par des prêtres.

Une fois de plus, le secteur médical est un révélateur de tendances de société. Ce que l'on pourrait prendre pour un simple gag de RP et un jeu infantile a en réalité des fondements sérieux. Nous autres Occidentaux n'avons pas le secours de la religion, même si la magie et le pouvoir des poupées ont toujours persisté au-delà de l'enfance. Angoissés et affligés, nous sommes à la merci des objets de transition. Car les peluches sont meilleures que les hommes. Un lavage en machine les ravive. Elles sont inconditionnellement d'accord avec nous, plus hygiéniques que les chiens et les chats, plus durables, plus fiables et moins chères. Or, nous avons un besoin urgent de zones de confort, d'endroits sûrs de régression pour des comportements enfantins, d'espaces douillets protégés, de doudous à caresser. Nous souhaitons que les grands prêtres de la médecine sacrifient à des rituels respectés, entourant nos égos malmenés d'attention et de compréhension. Car l'éléphant à la trompe tordue, l'écureuil fébrile, le lapin triste et le panda énucléé ne sont autres que nous, évidemment. La dynamique sociale actuelle des peluches reflète notre cohabitation névrosée. Nos amis imaginaires cadrent avec nos mondes virtuels. Notre fantaisie nous sauve de la fragilité ambiante. D'innombrables personnages fictifs issus de tous les médias peuplent les chambres d'enfants et les rêves des adultes. Nous nous réfugions au Pays imaginaire, en Terre du milieu, à Narnia et dans les bacs à fleurs du Ballenberg. La fièvre du petit singe grimpe et l'éléphanteau a mal au ventre. Le stéthoscope sur le cœur du nounours prend le pouls de notre époque.

Erhard Taverna 